\title{
A FREQUENCY AND VOLTAGE \\ CONTROLLABLE POWER SOURCE FOR LABORATORY USE
}

\author{
K. A. Nigim \\ Senior Member \\ University of Waterloo \\ Electrical and computer Engineering Dept. \\ knigim@ece.uwaterloo.ca
}

\author{
G. T. Heydt \\ Fellow \\ Arizona State University \\ Tempe, AZ, USA \\ heydt@asu.edu
}

\begin{abstract}
A technique is presented to generate a low voltage, frequency controllable power source for educational laboratory use. The proposed power supply has the merits of generating a sinusoidal AC low voltage waveform with controllable frequency and voltage from a wound rotor induction machine driven by a DC motor. The generator does not require a variable external excitation power source or any automatic voltage regulator. The presented configuration has the inherent capability of protecting the load under test from short circuit. The variable frequency generator is proposed as an educational laboratory power source for experiments in energy conversion, control, and electric power quality.
\end{abstract}

Keywords: Power engineering education; power supply; induction generator; frequency changer; pulse width modulation; power electronics.

\section{INTRODUCTION}

Since induction machines are not equipped with field windings, the AC excitation current for an induction generator must be supplied externally. The process, known as selfexcitation, entails excitation current that is supplied from a source that is continually replenished by the machine itself. This current magnetizes the reactive stator windings of the machine, providing a lagging current in these windings. This needs to be balanced by a source of leading reactive current. The leading reactive var current must be adjustable in order to be able to supply the demand at varying levels of load. Figure (1) lists different possible configurations of self-excited induction machine generating systems both for squirrel cage and wound rotor machines.

The external source commonly employed for self-excitation of induction generators is a capacitor bank across the machine terminals with large enough capacitance to provide the necessary leading current. The value of the effective capacitance must be controlled so that it will increase or decrease according to the level and type of load applied to the generator. Many researchers have focused on the induction machine as a generator; the self-excitation phenomenon giving terminal voltage as function of the rotor speed and load is presented in [14]. For a wound rotor machine, results are presented in references $[5,6]$. It is well known that the generated terminal voltage and frequency decrease with increasing load. The main control problem that has been addressed for the induction generator terminal voltage relates to the control concepts that guarantee smoothness of the voltage magnitude as the external vars are controlled. These methods ensure smooth voltage variation by incorporating a continuously controlled leading var source. Advantages and disadvantages of four alternative designs depicted in Figure (1) are listed in Table (1). A typical system (see Figure (1B)) involves the connection of a fully controlled thyristor bridge converter loaded with a large inductance. The converter is

"Proceedings of the 2002 American Society for Engineering Education Annual Conference \& Exposition Copyright O2002, American Society for Engineering Education" 
connected in parallel to a single bank of large excitation capacitors. The converter bridge is used to consume adjustable reactive lagging vars from the lines by varying the current circulating within the inductance. Since the controller is connected across the generator terminals, it must be capable of handling the full volt-amperes for which the machine is rated. It also generates harmonics and waveform distortion at the load. This can be a disadvantage especially for isolated and weak grids.

Wound rotor induction machines can result in lowering the volt-ampere rating needed for the controller, since the size of the electronic elements depends on the operating slip range. Therefore, if the slip is limited to approximately $10 \%$, then the controller volt-ampere rating will be limited to about $10 \%$ of the volt-ampere rating of the machine. The generated voltage will be sinusoidal and only one or two settings of the excitation capacitance are needed to cover operation from no load to full load. The system proposed in the present paper appears in Figure (1C).

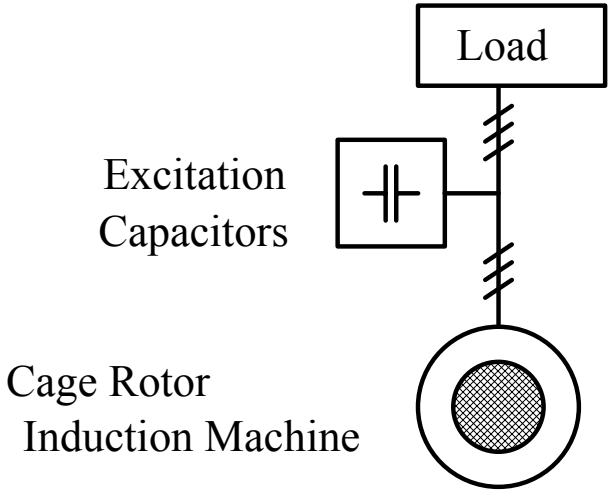

(A) Variable voltage and frequency system

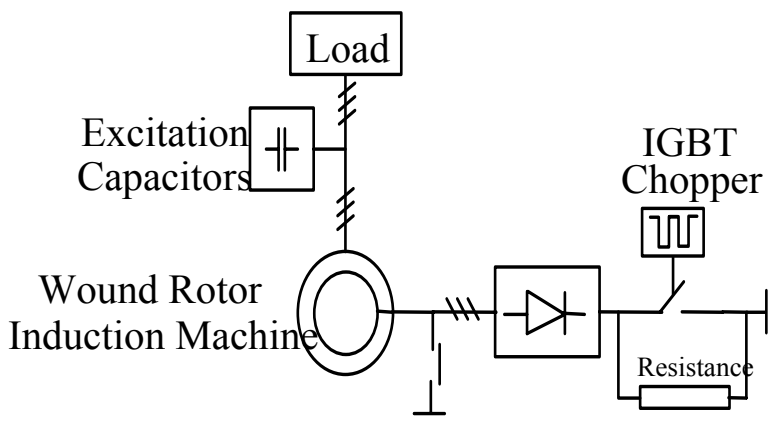

(D) Small voltage variation with frequency control system

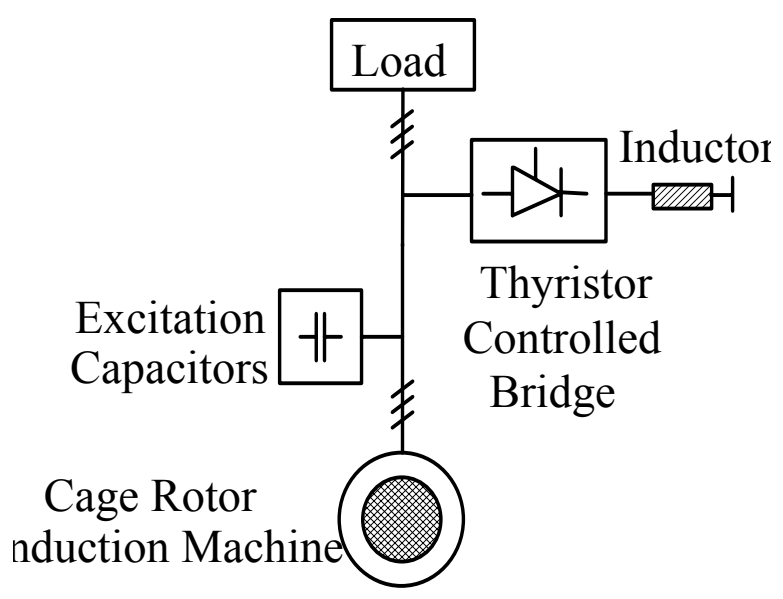

(B) Regulated voltage and frequency system (C)

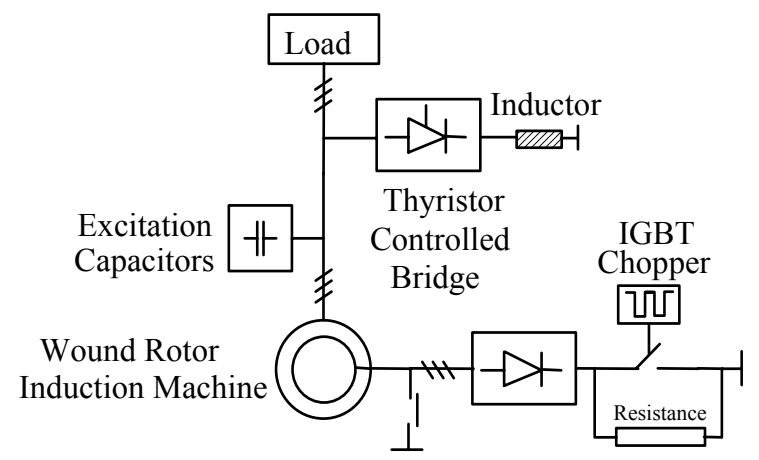

(D) Constant voltage and frequency control system

Figure (1) Four alternative techniques for using a wound rotor machine to generate power 
Table (1) Advantages and disadvantages of four alternative variable frequency source designs

\begin{tabular}{|c|c|c|c|}
\hline Design & Advantages & Disadvantages & Recommendation \\
\hline A & $\begin{array}{l}\text { - Easily constructed } \\
\text { - Low cost }\end{array}$ & $\begin{array}{l}\text { - Unregulated } \\
\text { voltage and frequency }\end{array}$ & Insensitive loads \\
\hline B & $\begin{array}{l}\text { - Robust generator } \\
\text { - Regulated voltage, } \\
\text { small frequency } \\
\text { variation }\end{array}$ & $\begin{array}{l}\text { - Waveform } \\
\text { distortion and high } \\
\text { grid influence } \\
\text { - Full volt ampere } \\
\text { rating of the electronic } \\
\text { system }\end{array}$ & $\begin{array}{l}\text { DC power supplies, } \\
\text { battery chargers, isolated } \\
\text { grid applications }\end{array}$ \\
\hline $\mathrm{C}$ & $\begin{array}{l}\text { - Regulated frequency, } \\
\text { small } \\
\text { voltage variation } \\
\text { - Low grid influence } \\
\text { - Slip dependent volt } \\
\text { ampere rating of the } \\
\text { electronic system. } \\
\text { - High efficiency }\end{array}$ & $\begin{array}{l}\text { - Expensive } \\
\text { machine }\end{array}$ & $\begin{array}{l}\text { AC power supplies, } \\
\text { isolated grid applications }\end{array}$ \\
\hline $\mathrm{D}$ & $\begin{array}{l}\text { - Constant voltage } \\
\text { - Constant frequency } \\
\text { - High efficiency }\end{array}$ & $\begin{array}{l}\text { Expensive } \\
\text { machine and system } \\
\text { - Waveform } \\
\text { distortion and high } \\
\text { grid influence } \\
\text { - Complex control } \\
\text { circuitry }\end{array}$ & $\begin{array}{l}\text { Constant voltage and } \\
\text { frequency power } \\
\text { supplies, isolated grid } \\
\text { applications }\end{array}$ \\
\hline
\end{tabular}

\section{MOTIVATIONAL ISSUES FOR A POWER ENGINEERING LABORATORY}

In the context of a modern undergraduate electrical engineering course of study, power engineering requires special attention. Many students are attracted to other areas as their life career choice. However, power engineering does offer pertinence and practicality, excellent employment opportunities, and challenging engineering problems. In order to make these points, laboratory work is quite appropriate [8]. While computer simulation has been utilized as a valuable tool in connection with laboratory instruction, and admitting that students have an affinity for the use of computer simulations, there are limits to the phenomena that can be effectively illustrated. Crow [9] mentions her reluctance on the sole reliance on simulation to illustrate realistic phenomena such as losses, measurement error, nonsinusoidal effects, and harmonic phenomena.

The variable frequency power source described above combines interesting control issues with power electronics in a challenging yet comprehensible context. The variable frequency source may be used to illustrate important points in power quality engineering.

"Proceedings of the 2002 American Society for Engineering Education Annual Conference \& Exposition Copyright O2002, American Society for Engineering Education" 
Furthermore, the generated voltage could be regulated using series capacitor compensation to improve stability. This offers a useful lesson relating to series compensation to the students.

Outside a laboratory environment, the variable frequency controlled induction generator can be used as a stand alone power source driven by different prime mover configurations such as wind turbine or low head hydro systems. Other potential applications include solar photovoltaic sources to produce three-phase power.

\section{SELF -EXCITATION IN A WOUND ROTOR INDUCTION MACHINE}

An induction machine connected to the mains driven below synchronous speed by a prime mover will experience a counter rotation between the rotor bars and the stator flux. Concomitantly, reversal of voltage and current from the machine windings to the mains occurs. Thus power is generated to the mains network and is governed by the following power limit equation of the induction machine,

$$
P_{1}=\frac{E_{t}^{2}\left[X_{m}+X_{s}-X_{e q}-2 r_{s}\right]}{2\left(r_{s}^{2}+\left(X_{m}+X_{s}\right) X_{e q}\right)}
$$

where $E_{t}$ is the terminal generated voltage depicted in the equivalent circuit shown in Figure (2), and

$X_{e q}=X_{s}+\left[\left(X_{m} X_{r}\right) /\left(X_{m}+X_{r}\right)\right]$

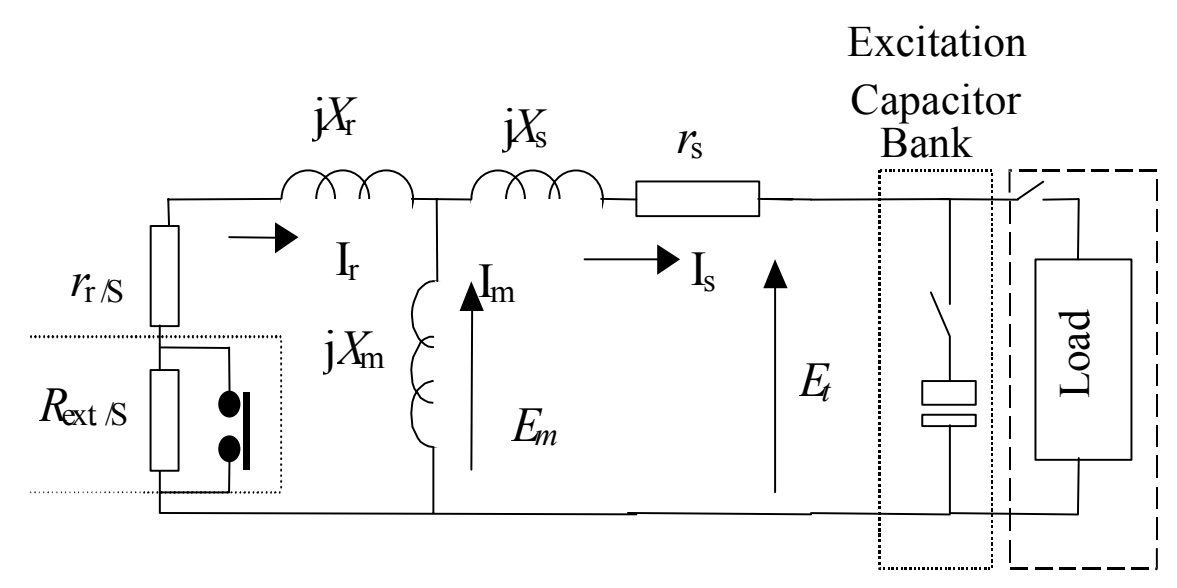

Figure (2) The equivalent circuit of the machine connected to the excitation capacitors and the load

The generated voltage and frequency are synchronously tied to the mains network. Therefore, the power delivered to the mains is entirely dependent on the machine characteristics. For isolated power generation, the self-excitation is adopted as a means for generating power from the machine in which the equivalent circuit as shown in Figure (2). Here, the power developed is no longer as indicated in Equation (1). The generated voltage and frequency is a

"Proceedings of the 2002 American Society for Engineering Education Annual Conference \& Exposition Copyright O2002, American Society for Engineering Education" 
function of multivariable elements mainly, the magnetizing reactance, the prime mover speed, the excitation capacitance leading vars, and the load applied across the generator terminals. The terminal voltage at the load can be simplified and given by [6],

$$
E_{t}=\frac{\left(f_{t} / f_{b}\right) E_{m}}{1-\left(f_{t} / f_{b}\right)^{2}\left(X_{L} / X_{C}\right)}
$$

Where $f_{\mathrm{t}}$ and $f_{\mathrm{b}}$ are the terminal and base frequencies in $\mathrm{Hz}$.

The following section is presentation of the machine performance during different loading conditions. This is based on energy balance principles to clarify how the generator will deliver power and to validate experimental results.

\section{ENERGY BALANCE IN A WOUND ROTOR INDUCTION MACHINE}

The self-excitation process in a wound rotor induction machine is very similar to a squirrel cage machine. To initiate the process, the slip rings are first shorted to enable the rotor current to circulate with minimum rotor resistance. With sufficient excitation capacitance connected across the terminals, voltage starts to build up due to the residual magnetism in the machine iron and the initial charge on the capacitor. After the voltage has reached its steady state, the rectifier bridge replaces the short circuit across the slip rings with the added rotor resistance connected across the DC bus as illustrated in Figure (3).

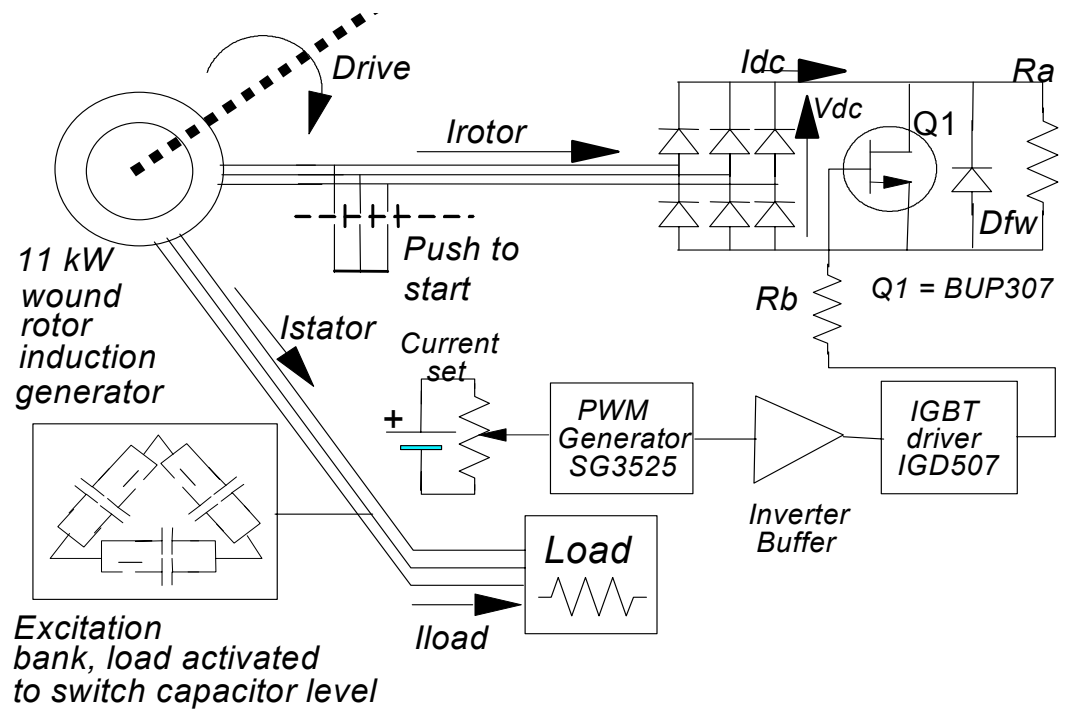

Figure (3) Experimental configuration for the generator and chopper circuit

\section{Active power balance}

The mechanical input power to the generator must supply the losses in the generator windings as well as the power delivered to the load. With reference to Figure (2), and disregarding mechanical and iron losses for simplicity, the following equations are valid, 
$\Sigma$ Active power in the system $=P=0$

$\Sigma P_{\text {stator copper losses }}+P_{\text {air gap }}+P_{\text {load }}=0$.

From these expressions, the slip $s$ is found,

$$
S=\frac{P_{\text {rotor copper losses }}}{P_{\text {stator } \quad \text { copper losses }}+P_{\text {load }}} .
$$

Equation (5) shows that the operating slip depends on the rotor copper losses and the load active power. Variation of the rotor resistance results in slip variations that, in turn, affect the generated frequency which are given by

$$
f_{t}=\frac{p}{4 \pi} \frac{w_{r}}{1-s}
$$

Where $p$ is the number of pair poles and $w_{r}$ is the rotor rotational speed in $\mathrm{r} / \mathrm{s}$.

To maintain the generated frequency within the desired slip operating range at the desired prime mover power, the maximum available power is limited to the rotor winding resistive value. In case of wound rotor machines this is possible. Thus the configuration exhibits the characteristic of regulating the frequency by changing the rotor winding resistance. The usual design of induction machines is based on the operation of small slip, typically about $5 \%$. This imposes a limit on the control circuitry to maintain high efficiency.

\section{Reactive power balance}

For the voltage to build up, the leading vars supplied by the capacitance must be large enough to supply the lagging var demand by the machine and the load. The level of leading vars depends on the operating voltage and current fed to the capacitors. At any instant, the capacitive reactance is given by,

$$
\begin{aligned}
& \sum \text { Reactive power within the system }=Q=0 \\
& \sum Q_{\text {stator }}+Q_{\text {rotor }}+Q_{\text {mag }}+Q_{\text {load }}-Q_{\text {cap }}=0 .
\end{aligned}
$$

From these expressions, the capacitive reactance as a function of the operating slip and frequency can be evaluated. Observations include the following:

- For a purely resistive load, $Q_{\text {load }}=0$, and the excitation leading vars $\left(Q_{\text {cap }}\right)$ must supply the machine windings lagging vars,

$$
Q_{\text {machine }}=Q_{\text {stator }}+Q_{\text {rotor }}+Q_{\text {mag }}
$$

This is the minimum capacitance required to sustain successful generation of voltage and will be a function of the magnetizing reactance of the machine.

- For a purely lagging load, the excitation capacitance must be large enough to supply the required leading vars. Using a fixed capacitance bank across the generator terminal and limiting the output voltage to the safe operating region simplifies the calculation of the values of impedance $X_{\mathrm{m}}$ (the sole unknown component value). Once $X_{\mathrm{m}}$ is calculated, using the open circuit machine magnetizing characteristics, the terminal voltage $E_{\mathrm{t}}$ is defined and hence the operating frequency is found as a function of rotor speed and load.

"Proceedings of the 2002 American Society for Engineering Education Annual Conference \& Exposition Copyright O2002, American Society for Engineering Education” 
Most recently a simplified mathematical presentation [7] to evaluate the machine magnetizing impedance as a function of the rotor speed and frequency was introduced for the squirrel cage machine. The analysis of the proposed induction generator source does not appreciably differ except for the inclusion of the rotor resistance as a variable and as a function of the chopper firing angle [5]. The reactive power balance, which is the same for the squirrel cage and the wound rotor machine results in a fourth, order equation. In this equation, the required excitation capacitance can be evaluated for the set conditions within the restriction given above. The prediction of the performance of the proposed variable frequency source is based on the methodology presented in [6].

\section{EXPERIMENTAL RESULTS FOR SYSTEM WITH A CHOPPER}

This section discusses preliminary experiments that were carried out using a $11 \mathrm{~kW}$ wound rotor induction machine. The machine was excited externally by using a delta connected capacitor bank. The experimental generator was implemented using a chopper circuit that was built and tested. Figure (3) illustrates the main elements used in the experiment. A variable speed DC motor drove the induction generator. The chopper circuit consisted of a 75 ampere, 1200 volt insulated gate bipolar transistor (IGBT) (Siemens BUP307). A dedicated IGBT driver module type IGD507 controlled the gate of the switching transistor. The driver module is switched by a pulse width modulated (PWM) signal at $200 \mathrm{~Hz}$. The ON period was controlled from zero to a maximum width of $5 \mathrm{~ms}$ by an analog signal fed to the PWM drive.

Through the preliminary experimentation, the feasibility of controlling both frequency and voltage by using a self-excited wound rotor induction machine controlled at the rotor side (while holding the excitation capacitor fixed) was successfully initiated and provided power above $60 \%$ of the machine rating as indicated in Figure (4).

It is noted that the generated terminal voltage should be sinusoidal with low order harmonic content. Harmonics depend on the saturation of the stator iron. The level of harmonics was verified in experiments as exemplified by Figure (5). In this figure, a load of 17 A (rms), $278 \mathrm{~V}$ (rms, line - neutral) was recorded. Since the control is applied to the rotor side, and the generated voltage is supplied through the stator, this outcome should not be surprising. If a squirrel cage machine were employed, control would need to be applied at the stator, and this would corrupt the generated voltage. The generated terminal voltage was observed during the operation of the chopper circuit. The effect of switching the transistor ON and OFF did not cause waveform distortion.

\section{INSTRUCTIONAL POSSIBILITIES USING A VARIABLE FREQUENCY POWER SOURCE}

The variable frequency power source described above has application as a general purpose laboratory power source. In the context of power engineering education, the source has special value to demonstrate transformer and reactor losses as a function of frequency. A particular application is in variable speed drives. For synchronous motors, the adjustment of speed can be accomplished in a control loop. The same is true as a variable speed drive for induction motors. In these cases, instrumentation of the drive is possible and key issues of induction motor and synchronous motor modeling can be demonstrated. Unbalanced cases can be demonstrated by insertion of reactors in the phases of the controlled motor supply. A particularly interesting demonstration concerning the variation of luminous color output of electroluminescent panels may be demonstrated - even to the kilowatt level - using the variable frequency power source.

"Proceedings of the 2002 American Society for Engineering Education Annual Conference \& Exposition Copyright O2002, American Society for Engineering Education" 

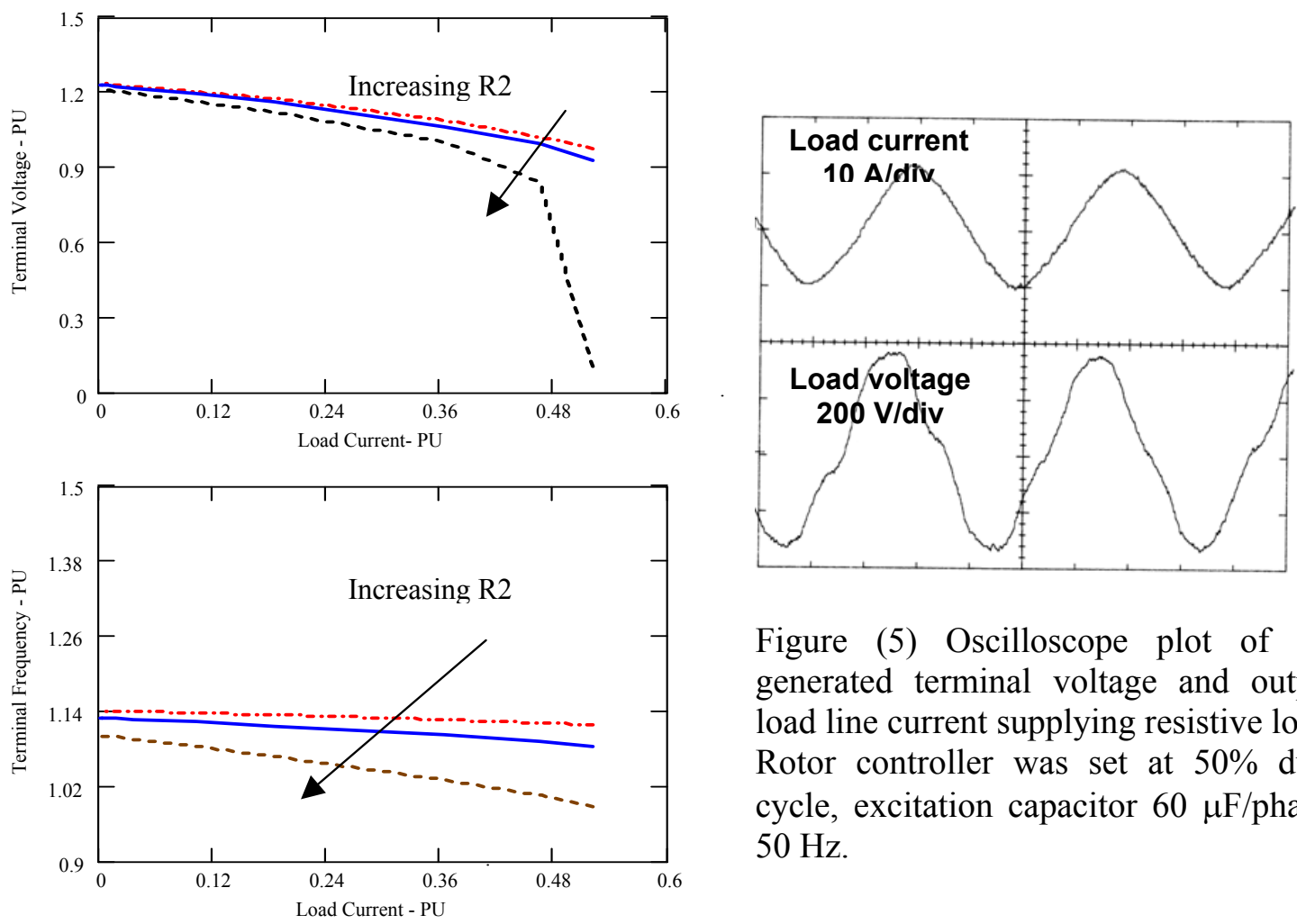

Figure (5) Oscilloscope plot of the generated terminal voltage and output load line current supplying resistive load. Rotor controller was set at $50 \%$ duty cycle, excitation capacitor $60 \mu \mathrm{F} /$ phase, $50 \mathrm{~Hz}$.

Figure (4) Experimental results for an $11 \mathrm{~kW}$ induction generator indicating successful generation of voltage as the chopper angle is varied resulting in variable resistance effect across the slip rings

Students in a general undergraduate electrical engineering program will benefit from the design of a closed loop controller for the voltage regulation of the variable frequency power source: in this application, a voltage sensor is used in a feedback control for the PWM inverter in the power source.

A typical design is shown in Figure (6). This makes an interesting semester project in feedback control and power electronic switching evaluation for undergraduate students.

\section{CONCLUSIONS}

This paper describes a proposed system that serves as a source of controllable frequency and voltage. The system uses a wound rotor induction machine controlled at the rotor side. A main feature of the proposed system is that it allows control of both voltage and frequency in a simple configuration. This is important since voltage can be stepped down or boosted with a transformer, while control of frequency would otherwise require sophisticated circuitry that distorts the generated waveform. The system could be viewed as an isolated source of sinusoidal power with inherent short circuit protection. Educational applications include 
laboratory experiences in variable speed drives, modeling, and control. The power electronic application and the control design are found to be motivational for undergraduate students in power engineering. Other applications outside the laboratory context include wind generators, small hydro plants, and photovoltaic generation to a three phase grid.

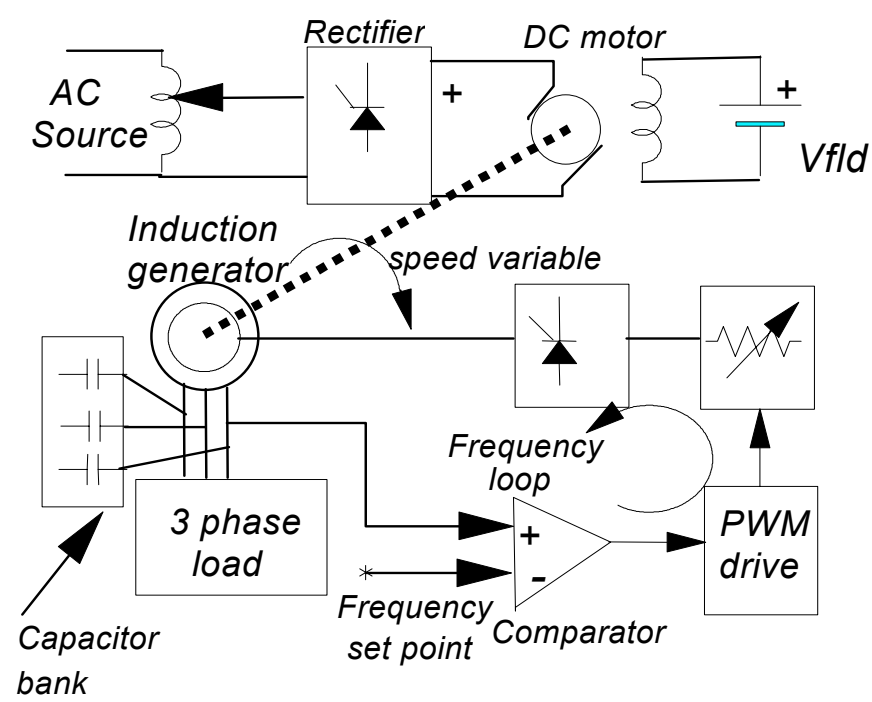

Figure (6) Feedback controller for the variable frequency power supply

\section{REFERENCES}

[1] J. M. Elder, B. E. Boys, J. L. Woodward, "Self-excited Machine as a Small Low Cost Generator," IEE Proceedings, Vol. 131, Pt. C, No. 1, January 1984, pp. 33-41.

[2] A. H. Al-Bahrani, N. H. Malik "Voltage Control Of Parallel Operated Self Excited Induction Generators," IEEE Transaction on Energy Conversion, Vol. 8, No. 2 June 1993, pp. 236 - 242.

[3] N. H. Malik, A. A. Mazi, "Capacitance Requirements for Isolated Self Excited Induction Generators," IEEE Transactions on Energy Conversion, Vol. EC-2, March 1987, pp. 62 - 69.

[4] L. Shridhar, B. Singh, C. S. Jha, "A Step Towards Improvements in the Characteristics of Self Excited Induction Generator." IEEE Transactions on Energy Conversion, Vol. EC-8, No. 1, March 1993, pp. $40-46$.

[5] K. A. Nigim "Control of Frequency and Voltage in Wound Rotor Self-Excited Induction Generator," Journal of Engineering and Applied Science, Cairo University, Egypt, Vol. 47, no. 2, April 2000.

[6] L. Quazene, G. McPherson “Analysis of the Isolated Induction Generator," IEEE Transactions on Power Apparatus and Systems, Vol. PAS-102, No. 8, August 1983, pp. 2793 2798.

[7] T. F. Chan "Capacitance Requirement of Self Excited Induction Generators," IEEE Transactions on Energy Conversion, Vol. 8, No. 2, June 1993, pp. $304-311$.

[8] G. G. Karady, G. T. Heydt, "Increasing student interest and comprehension in power engineering at the graduate and undergraduate levels," IEEE Transactions on Power Systems, vol. 15, No. 1, February 2000, pp. $16-21$.

[9] G. Karady, M. Crow, G. Heydt, S. Iwamoto, K. Olejniczak, "Role of Laboratory Education in Power Engineering: Is the Virtual Laboratory Feasible?" Proceedings of the IEEE - PES 2000 Summer Meeting, Publication 0-7803-6423-6/00, Seattle, WA, July, 2000.

"Proceedings of the 2002 American Society for Engineering Education Annual Conference \& Exposition Copyright O2002, American Society for Engineering Education" 